\title{
Üniversite Öğrencilerinin \\ Kimlik Oluşumu ve Demografik Bilgileri
}

\author{
Dr. Aytaç GÖĞÜŞ \\ Sabancı Üniversitesi, Bireysel ve Akademik Gelişim Merkezi, İstanbul / Türkiye
}

\section{Özet}

Bu niceliksel çalışmanın amacı, üniversite öğrencilerinin kimlik oluşumu ile bazı demografik özellikleri arasındaki ilişkiyi araştırmaktır. Bu çalışma 2010-2011 Güz Dönemi’nde Sabancı Üniversitesi lisans öğrencilerine uygulanmıştır. Bu çalışmada, kimlik ölçeğinin üç alt boyutu olan kişisel kimlik, sosyal kimlik ve kolektif kimlik ile bazı demografik bilgiler arasındaki ilişkiler incelenmiştir. Sonuçlara göre, cinsiyet, öğrencilerin kayıtlı olduğu fakülte türü, öğrencilerin haftalık ders çalışma saati ve sosyal aktivite saati ile kişisel kimliğin ilişkili olduğu görülmektedir. Sosyal kimlik ile öğrencilerin sosyal aktiviteler için ayırdığı zaman arasında ilişki bulunmaktadır. Kolektif kimlik ile öğrencilerin kaçıncı sınıfta olduğu ve ailenin gelir durumu arasında ilişkiler vardır. Kimlik gelişimini desteklemek için hazırlanan programlarda ve öğrenci bireysel destek programlarında bu araştırmanın sonuçları göz önüne bulundurularak gerekli eğitim seminerleri ve destek programları hazırlanabilinir. Bu programlar, öğrencilerin üniversite hayatlarının kalitesini geliştirmekte

* Tel: +902164839485 E-posta: agogus@ sabanciuniv.edu

(C) 2013 Kalem Eğitim ve Sağlık Hizmetleri Vakfı. Bütün Hakları Saklıdır. ISSN: 2146-5606 
ve kimlik oluşumlarını desteklemekte önemli bir rol oynayabilir.

Anahtar Kelimeler: Kimlik ölçeği; Kişisel kimlik; Sosyal kimlik; Kolektif kimlik; Üniversite lisans öğrencileri.

\title{
Identity Formation and Demographic Information of University Students
}

\begin{abstract}
The aim of this quantitative study is to investigate the relationship between identity formation and demographic information of university students. This study was implemented in the 2010-2011 Fall semester among the undergraduate students of Sabanc1 University. The study examined the relationship between same demographic information and the three sub-dimensions of the identity scale; personal identity, social identity and collective identity. The results indicate that students' gender, faculty type, weekly study hours and weekly social activity hours are related with their personal identities. The social identity of a student is related with weekly social activity hours. The collective identity of a student is related with the student's grade year and family income. The results of this research can be used in programs to be prepared to support identity development, personal support programs for students, and in the development of educational seminars and other support programs. These programs can play an imprortant role in the improvement of a student's university life-quality and identity formation.
\end{abstract}

Keywords: Identity scale; Personal identity; Social identity; Collective identity; University undergraduates.

\section{Extended Summary}

Identity has been the subject of widespread theoretical and empirical inquiry for more than 50 years. The first studies in this field is based on Erikson's (1950) works on identity and these works led to, 
many research studies focusing mostly on the identity categories (eg, ego identity, personal identity, social identity, collective identity), identity development and emerging adulthood. Identity development is a life-long process that is particularly important during late adolescence and emerging adulthood, eras, when individuals have to make important life decisions. Although this process has been studied from different theoretical perspectives, all authors recognize its complexity in terms of the interaction between person and context. The earliest studies on identity development has been focused on personal identity (Côté, 2006; Côté \& Levine, 2002; Schwartz, Zamboanga, Weisskirch, $\&$ Wang, 2010) and has placed primary emphasis on the identity status model (Marcia, 1966), which posits exploration of and commitment to prospective life alternatives (Schwartz et al., 2010). Côté and his colleagues (eg, Côté, 1996; Côté \& Levine, 2002) have focused on delineating the ways in which identity is developed through transactions with society and social interactions (Schwartz et al. 2010). The personal identity studies have focused on the ways in which goals, values, and beliefs are consolidated during the transition to adulthood (Schwartz, 2006) and on how this sense of identity consolidation relates to indices of well-being and distress in young people (Schwartz, 2007; Schwartz et al. 2010).

Cheek and his colleagues (eg, Cheek, 1989; Cheek \& Hogan, 1983; Cheek, Underwood \& Cutler, 1985; Cheek, Tropp, Chen \& Underwood, 1994; Cheek \& Tropp, 1995; Hogan \& Cheek, 1983) have characterized the identity as three structural categories (personal, so- 
cial, and collective identity), each of them having significance for an individual's psychosocial functioning. Individuals can vary in the importance they give to these three aspects of identity in their identity formations (Cheek et al., 1994). Personal identity concerns one's personal goals, values, ideas, emotions, and feelings. Social identity concerns the self public image, as in one's popularity, attractiveness, and reputation. Collective identity concerns the self-concept that relate to one's race, gender, ethnic background, religion, and feelings of belonging in one's community (Cheek, 1989; Cheek et al., 1994; Wade \& Brittan-Powell, 2000).

\section{Purpose}

This quantitative research aims to investigate the interplay between university students' identity formation and demographic characteristics. The results are valuable in enhancing the quality of students' university life, helping them to support their identity formation and academic success.

This study uses the identity questionnaire (Cheek \& Tropp, 1995) which has three sub scales: (1) Personal Identity Scale represents one's private self-conception and subjective feelings of continuity and uniqueness; (2) Social Identity Scale represents one's public image as presented through social roles and relationships; (3) Collective Identity Scale represents one's social self-conception that pertains to communal or collective aspects (eg, feelings of belonging belonging in one's community). 


\section{Participants}

Participants are the undergraduate students of Sabancı University. 505 (280 male, 225 female) students completed the survey instruments. Average age is 20. Seventy six per cent of the students $(n=382)$ from metropols, $19 \%$ of the students $(n=95)$ from provinces, 5 $\%$ of the students $(n=25)$ from small towns studied in this small international university with around 3500 students in Istanbul in the largest metropolitan city of Europe. From the total of 505 participants, $49 \%$ of the students $(n=247)$ were freshmen, $23 \%$ of the students $(n=114)$ were sophomore, $15 \%$ of the students $(n=68)$ were junior, $13 \%$ of the students $(n=76)$ were senior. Fifty four per cent of the students $(n=270)$ were living in dorms. Considering the faculties, sixty five per cent of the students $(n=328)$ were registered in the Faculty of Engineering and Natural Sciences and $45 \%(n=177)$ were registered in the Faculty of Art and Social Sciences. Students of the Faculty of Engineering and Natural Sciences were overrepresented, as they form the majority of university population.

\section{Procedure}

The survey instrument, the aim of the research and the consent form were mentioned to undergraduate students via e-mail and also by means of students who took the course of Project 102 in the 2010-2011 fall semester. 530 volunteer students participated in this study. Each application lasted approximately half an hour. From the total of 530 volunteer participants, 25 students did not respond to all items in the survey. Therefore, only 505 students' responses were analyzed. There 
were two sections in the instrument: demographic information (eg, faculty, sex, socio-economic status etc.) and the Identity Questionnaire (IQ) about identity formation (Cheek et al., 1994). Excel and SPPS were used during analyses of the data.

\section{Identity Questionnaire}

Identity Questionnaire was created by Cheek and Tropp (1982) and translated into Turkish by Hamit Coşkun (2004). The identity questionnaire has three scales: the Personal Identity Scale, the Social Identity Scale, and the Collective Identity Scale. The Personal Identity Scale (10 items) represents one's private self-conception and subjective feelings of continuity and uniqueness. The Social Identity Scale (7 items) represents one's public image as presented through social roles and relationships. The Collective Identity Scale (8 items) represents one's social self-conception that pertains to communal or collective aspects (eg, religion, racial ethnic group, and feelings of belonging in one's community). Each item is an identity characteristic representative of one of the three identity domains (Coşkun, 2004).

Coşkun (2004) examined the Turkish translation of the Identity Questionnaire's validity and reliability. 275 university students participated in the research. The findings regarding the questionnaire's structure and criterion validity indicate that the sub-scales (personal, social and collective identity) reflect one whole structure, work in harmony with one another and each have unique structures. The findings also set forth that the reliability (test-retest) coefficients $(\mathrm{N}=160)$ regarding the whole test, and the internal consistency and the score 
constancy of the sub-scales are at an adequate level.

\section{Results}

According to correlation results, there is a high level of significant relationship between all sub-identity scales. No significant relationships among demographic information on age, school success average, grade year, the longest stay of residency, current place of residency (accommodation), mother's educational background, father's educational background and sub-identity scales were not found. The aspects where significant relationships between sub-identity scales and demographic information can be summarized as below:

1. There is a significant relation between personal identity and gender at a level of $0.01(r=-0.29)$

2. There is a significant relation between personal identity and the type of faculty at a level of $0.05(r=0.09)$.

3. There is a significant relation between personal identity and weekly study hours at a level of $0.05(r=0.10)$.

4. There is a significant relation between personal identity and weekly social activity hours at a level of $0.05(r=0.10)$.

5. There is a significant relationship between social identity and weekly social activity hours at a level of 0.01 ( $r=0.12)$.

6. There is a significant relationship between collective identity and grade year at a level of $0.05(r=-0.10)$.

7. There is a significant relationship between collective identity and family income at a level of $0.01(r=0.14)$.

The above results can be interpreted as below: 
- According to gender, being a woman and the personal identity are related.

- As taking in consideration the students' faculty and identity, being enrolled to each other in the Arts and Social Sciences Faculty increases the degree of personal identity positively.

- As the weekly hours for studying and social activities increase, the degree of the student's personal identity increases.

- Social identity degree increases as weekly hours for social activities increase.

- As the grade year increases, the degree of collective identity decreases.

- As the family income increases, the degree of collective identity increases.

\section{Discussion and Conclusion}

Taking in consideration the students' academic activities, there is a significant relationship between studying and personal identity. Students bring their personal goals to the forefront by spending more time for studying. In addition to this, there is a relationship between students' participation in social activities and their personal and social identities. Students bring both their personal dreams, expectations and opinions as well as their social behavior and impression on others through their social activities. Students' academic and social experiences have an impact on the development of their personal and social 
identities. There is a decrease in students' level of collective identity as students pass on to higher grades. During their university years, students bring their personal goals and interaction with their social environment as opposed to their ethnic roots, religions, languages and family backgrounds. The way in which these students manage their fears and concerns may be related with their wishes to have independent and different personalities and receive acceptance from their social environments. As Turkey goes through a transition from being a collective society to an individualist society, women in higher education bring their opportunity of self-expression to the forefront.

Although one would expect the students of the Faculty of Arts and Social Sciences to highlight their social identities, their personal identity comes to the forefront. This may be due to the overrepresentation of the Faculty of Engineering and Natural Sciences students who make up the majority of the university.

The studies on personal, social and collective identities have investigated how these three dimensions of identity functions at high and low levels (Wade \& Brittan-Powell, 2000). Schlenker and Weigold (1990) suggest that an individual with a strong personal identity is social and autonomous, and feels the need to be unique. However, someone with a strong social identity tries to act according to the group instead of being autonomous, although he or she is social as well (Wade \& Brittan-Powell, 2000). Additionally, personal identity has been found to be related to an achieved ego identity, whereas social identity has been found to be related to a foreclosed ego identity (Berzonsky, 
Trudeau \& Brennan, 1988; Wade \& Brittan-Powell, 2000). In general, a strong personal identity is related to decision-making based on personal reasons and profit, whereas a strong social identity is related to decision-making based on social reasons and profit (Wade \& Brittan-Powell, 2000).

Unlike the general expectation, aspects of the collective identity come to the forefront as family income increases. $48 \%$ of Sabanc1 University students come from middle class families whereas $50 \%$ come from upper class families. $76 \%$ of the students come from metropolitan cities (Istanbul, Ankara, Izmir) and $19 \%$ come from other neighboring cities. Even if a student comes from an upper class family, his or her feeling of belonging to the society and self-esteem are highlighted. Collective identity has also been investigated for its relationship to self-concept and self-esteem in individuals from a variety of social or demographic groups (eg, Hengst, 1997; Marmarosh \& Corazzini, 1997; Wright \& Forsyth, 1997). According to the results of this research, self-esteem increases when one's collective identity is an important aspect of one's self-concept (Wade and Brittan-Powell, 2000).

As some studies on identity suggest (Berman, Kennerley \& Kennerley, 2008; Ferrer-Wreder, Montgomery \& Lorente, 2003), programs to support university students' identity development should be prepared. The result of this research can be used in programs that support identity development, individual counseling programs, educational seminars, and in the development of other support programs. 
These programs can play a important role in the improvement of student's university life-quality and identity formation.

\section{Giriş}

Bireyler, ergenliğin bitişi ve genç yetişkinliğe geçiş döneminde kimlik duygusu kazanır. Kendileri hakkında ve kim oldukları konusundaki algılarını, hayattan neler beklediklerini, sosyal ortamlarındaki ilişkilerini, ilgilerini ve yeteneklerini değerlendirirler. $\mathrm{Bu}$ soruların cevaplarını sosyal çevreden etkilenmeden vermeleri mümkün değildir. $\mathrm{Bu}$ yüzden gençlerin kimlik oluşumunda, çok geniş bir sosyal çevreyle etkileşimlerinin izleri görülür. Kendini geliştirmekte, bir mesleğe hazırlanmakta ve ekonomik olarak geçimini sağlamakta olan genç, hem önceden gelen kimlik özelliklerini değerlendirir hem de sosyal roller ve değerlere uygun olarak kendi kişiliğini şekillendirir (Demir, 2009). Sağlıklı bir kimlik edinme hem kişisel hem de toplumsal açıdan önem taşımaktadır.

50 y1lı aşkın bir süredir kimlik, geniş bir kuramsal ve deneysel araştırmanın konusu olmuştur. Bu alanın başlangıcı Erikson’un (1950) kimlik üzerindeki çalışmalarına dayanır ve bu çalışmalar, çoğunlukla kişisel kimliğe yoğunlaşan kimliksel gelişim çalışmalarının doğuşuna neden olmuştur (Côté, 2006; Côté ve Levine, 2002; Schwartz, Zamboanga, Weisskirch ve Wang, 2010). Başlangıçta, kişisel kimlik kavramı ile gelecekteki hayat alternatiflerini keşfetmeyi ve uygulamayı birincil kimlik gelişimi süreci olarak tanımlayan bir kimlik statüsü modeli ön plana çıkarılmıştır (Marcia, 1966; Schwartz ve ark., 2010). Daha sonraları, kişisel kimlik üzerine yapılan araştırmalar (örneğin, 
Côté, 1996; Côté, 2006; Côté ve Levine, 2002; Schwartz ve ark., 2010) kimliğin toplumsal etkileşimler aracılığıyla nasıl şekillendiğine ve sosyal kaynak edinmek için nasıl pazarlığının yapılabileceğine yoğunlaşmıştır. Kişisel kimlik üzerine çeşitli akımlar, yetişkinliğe geçiş sürecinde hedeflerin, değerlerin ve inançların nasıl sağlamlaştığı (Schwartz, 2006) ve bu kimliksel sağlamlaşmanın genç insanlarda refah ve stressiz hayatla ne kadar ilişkili olduğu sorularına yoğunlaşırlar (Schwartz, 2007; Schwartz ve ark., 2010).

Erikson (1950)'a göre, üniversite dönemi, genç bir insana yetişkinlik sorumluluklarını erteleyebileceği ve çeşitli kimliksel sorumlulukları yerine getirebileceği bir dönem sunar. Gerçekten de, Meilman (1979) ergenlikte ego kimlik statüsü araştırmasında ergenlerin 21 yaş ve sonrasına kadar sağlam ve sabit bir kimlik oluşturamadıklarını keşfetmiştir. Erikson (1968), kimlik oluşumunun geç ergenlik döneminde refah içinde yaşamaktaki önemli rolünü açıklamıştır (akt; Luyckx, K., Schwartz, S. J., Soenens, B., Vansteenkiste, M. ve Goossens, L. 2010). Côté ve Roberts (2003)'a göre, üniversite mezunlarının yalnızca üçte biri, topluma entegre olmayla ilgili kimliksel meselelerini yirmili yaşların sonlarına doğru halledebilmişlerdir. Yüzde 20'si ise bu konuda akranlarına göre gelişimsel gecikme yaşamaktadır. Bu geç kimliksel gelişim sürecinde olanlar için, "gelişmekte olan erişkin" adlı yeni bir gelişim dönemi tanımı ortaya çıkmıştır (Arnett, 2000).

Günümüzde yaşanan sosyo-yapısal toplumsal değişimler sebebiyle, kimlik oluşumu geç ergenlik ve yirmili yaşların sonlarını kapsayan "gelişmekte olan erişkin” dönemine kadar uzanır (Arnett, 2004). 
Birçok insanın yetişkinliğe yükseköğretim aracılığıyla geçiyor olması da yetişkinliğe geçişi geciktirir. Fakat hem geçişsel stres etkenleri hem de gelmekte olan yetişkinlik yılları, yeni beliren yetişkinlik dönemini oldukça riskli ve refahtan uzak bir dönem yapmaktadır (Côté ve Levine, 2002). Diğer taraftan, kimlik "krizi” son bulmuş olmasına rağmen, birçok yetişkin kimliksel sorumluluklarını yeniden keşfetmeye ve tanımlamaya ömürleri boyunca devam ederler (Stephen, Fraser ve Marcia, 1992). Kimlik konusundaki bazı araştırmalar (Berman, Kennerley ve Kennerley, 2008; Ferrer-Wreder, Montgomery ve Lorente 2003), üniversite öğrencilerinin kimlik gelişimini destekleyecek programların sağlanmasını önerirler.

Kimlik; kişisel değerler, düşünceler, duygular, algılar gibi bireye özgü özelliklerin (kişisel kimlik), aidiyet duygusu, beğenilme, onay görme, ün gibi sosyal gruplarla ilişkilerin (sosyal kimlik) ve kişinin 1rk, din, dil, ulus, vatandaşl1k ve politik etkinlikleri gibi özelliklerinin (kollektif kimlik) bir bütünü olarak görülmüştür (Coşkun, 2004). Cheek ve meslektaşları (Cheek, 1989; Cheek ve ark., 1994) kimliği, her biri kişinin psiko-sosyal işlevlerinde farklı bir öneme sahip üç yapısal kategoriye (kişisel kimlik, sosyal kimlik, kolektif kimlik) ayırırlar. Kişisel kimlik insanın kişisel değerleri, fikirleri, hedefleri, duyguları ve devamlılık ile eşsizliğe dair öznel duyguları ile ilgilidir. Sosyal kimlik, kişinin diğer insanlarla ilişkilerini ve toplumsal imajını, popülerliğini, çekiciliğini ve unvanını içerir (Cheek, 1989; Cheek ve ark., 1994; Wade ve Brittan-Powell, 2000). Sosyal kimlik kuramı, kişisel kimlikten ayrı olarak, bireyin ait olduğu veya ait olduğunu hissettiği gruplar ara- 
c1lığgyla kimlik oluşturmanın önemini vurgulamaktadır (Tajfel, 1982; Tajfel ve Turner, 1986; Turner, 1978). Kimlik gelişim araştırmalarında, Sosyal Kimlik kuramının yaklaşık son 40 yılda alana katkıları vardır (Arnett, 2000, 2001; Briggs ve Cheek, 1986; Cheek, 1982, 1983; Cheek ve Hogan, 1983; Coşkun, 2000, 2004; Erikson, 1963, 1968; Lamphere ve Leary, 1990; Miller ve Thayer, 1988; Penner ve Wymer, 1983; Schlenker ve Weigold, 1990), ama Kişisel Kimliği ve Sosyal Kimliği ölçme girişimi ilk kez Cheek ve Briggs (1982) tarafından başlatılmış ve Kimlik Ölçeği geliştirilmiştir. Başlangıçta sadece Kişisel Kimlik ve Sosyal Kimlik boyutlarını içeren Kimlik Ölçeği’ne yeni maddeler eklenerek üçüncü bir kimlik ölçeği boyutu olan Kolektif Kimlik, ölçme ve değerlendirilmeye dâhil edilmiştir (Cheek, 1982, 1983; Cheek ve Hogan, 1983; Cheek, Underwood ve Cutler, 1985; Cheek ve ark., 1994; Cheek ve Tropp, 1995; Hogan ve Cheek, 1983). Kolektif kimlik kişinin, 1rk, toplumsal cinsiyet, etnik arka plân ve din gibi toplumsal ve demografik gruplara ait olma algisıyla ilgilidir (Cheek, 1989; Cheek ve ark., 1994; Wade ve Brittan-Powell, 2000). Araştırmalar kolektif kimliğin daha çok, azınlık ırkı mensubu, kolektivist yönelimi güçlü (Cheek ve ark.,1994) ve etnik kimliklerini kişisel algılarında merkezî bir yere koyan kişilerde belirgin olduğunu gösterir (Tropp, 1992). Ayrıca, kolektif kimliği güçlü fakat kişisel kimliği zayıf kişilerin, kolektif kimliği zayıf bireylere kıyasla kendi ülkeleri hakkında daha olumlu bir görüş bildirdikleri vurgulanmıştır (Kowalski ve Wolfe, 1994). Bireyler kendilerini tanımlarken, kimliğin bu üç boyutuna farklı şekillerde ağırlık verebilirler (Cheek ve ark., 1994). 
Kimlik oluşumu ile ilgili araştırmalar, kişinin sosyal sermayesi (sosyal çevresi, kurduğu sosyal ağ ve edindiği değerler) ve kişisel sermayesi (benlik saygısı, hayattaki amaçlılık ve benlik yeterliği) yüksek olan gençlerin sağlıklı bir kişisel gelişim geçirdiklerini vurgulamıştır (Côté, 1996, 2006; Schwartz, 2006, 2007). Özetle, kimlik gelişimi, hayat boyu süren ve özellikle ergenlik sonu ve yetişkinlik başlangıcında belirginlik kazanan, bireylerin hayatlarına dair önemli kararlar verdikleri bir süreçtir. Bu süreç birçok farklı kuramsal perspektiften incelenmiş olsa da, tüm yazarlar bu sürecin kişi ile bağlam arasındaki etkileşim açısından oldukça karmaşık olduğunu belirtirler. Kimlik Ölçeği'nin üç alt ölçeği vardır: (1) Kişisel Kimlik Ölçeği, bir insanın kendisine ve devamlılık ile eşsizlik gibi öznel duygulara dair algısını; (2) Toplumsal Kimlik Ölçeği, bir insanın, toplumsal rol ve ilişkiler tarafından şekillendirilmiş kendi kamusal imajını; (3) Kolektif Kimlik Ölçeği ise bir insanın komünal veya kolektif olgulara (örn. kendi topluluğuna ait olma hissi) dair kendi toplumsal algısını temsil eder (Cheek ve Hogan, 1983; Cheek, Underwood ve Cutler, 1985; Cheek ve ark., 1994; Cheek ve Tropp, 1995; Coşkun, 2004).

$\mathrm{Bu}$ çalışmanın amacı, üniversite öğrencilerinin kimlik oluşumu ile demografik özellikleri arasındaki ilişkiyi araştırmaktır. Sonuçlar, öğrencilerin üniversite hayatlarının kalitesini geliştirmekte ve kimlik oluşumlarını desteklemekte önemli bir rol oynar. Bu çalışma, sağlıklı kimlik gelişimini destekleyecek uygulamalı çalışmalar için bir kaynak sağlayacaktır. 


\section{Yöntem}

\section{Araştırmanın Modeli}

Bu çalışma 2010-2011 Güz Dönemi’nde Sabancı Üniversitesi lisans öğrencilerine uygulanmıştır. Veri toplamada kullanılan anket, araştırmanın amacı ve rıza formu, e-mail yoluyla ve Project 102 dersini alan öğrenciler aracılığıyla lisans öğrencilerine iletilmiştir. Bu araştırmaya 530 gönüllü öğrenci katılmıştır. Her uygulama yaklaşık olarak yarım saat sürmüştür. 530 gönüllü katılımcıdan 25 öğrenci, anketteki bütün sorulara cevap vermediği için sadece 505 öğrencinin cevab1 analize dâhil edilmiştir. Anketin iki bölümü bulunmaktadır: demografik bilgiler (örneğin; fakülte, cinsiyet, sosyo-ekonomik durum vs.) ve kimlik bilgilerini içeren Kimlik Anketi (KA) (Cheek ve ark., 1994). Verilerin analizi için Excel ve SPPS programları kullanılmıştır.

\section{Çalışma Grubu}

Katılımcılar, Avrupa'nın en büyük metropol şehri olan İstanbul'da yer alan, 3500 nüfuslu uluslararası bir vakıf üniversitesi olan Sabancı Üniversitesi'nde eğitim gören lisans öğrencileridir. 505 (280 erkek, 225 kadın) öğrenci ankete katılmıştır. Ortalama yaş 20’dir. Öğrencilerin \% 49'u 1. sinıf (n=247), \% 23'ü 2. sinıf (n=114), \% 15'i 3. sınıf (n=68), \% 13’ü ise 4. sınıf $(n=76)$ öğrencisidir. Öğrencilerin \% 54 'ü (n=270) yatakhanelerde kalmaktadır. Kayıtlı oldukları fakültelere göre, öğrencilerin \% 65’i $(n=328)$ Mühendislik ve Doğa Bilimleri Fakültesi ve \% 45’i ( $n=177)$ Sanat ve Sosyal Bilimler Fakültesi öğrencisidir. Mühendislik ve Doğal Bilimler Fakültesi öğrencileri, üniversite nüfusunun çoğunluğunu oluşturdukları için fazladan temsil edilmiş- 
lerdir.

\section{Demografik Bilgiler}

Anketin bütün sorularına cevap veren 505 lisans öğrencisinin kişisel bilgileri özeti aşağıdaki gibidir:

\begin{tabular}{|c|c|}
\hline Cinsiyet & $\% 55$ kadın, \% 45 erkek \\
\hline Sinif & $\begin{array}{l}\text { \% 49'u 1. sinıf, \% 23’ ̈̈ 2. sinıf, \% 15'i 3. sinıf, \% } 13 \text { 'ü } 4 . \\
\text { sinıf }\end{array}$ \\
\hline Ailesinin geliri & $\begin{array}{l}\% 0 \text { çok düşük, } \% 2 \text { düşük, } \% 48 \text { orta, } \% 47 \text { yüksek, } \% 3 \\
\text { çok yüksek }\end{array}$ \\
\hline Haftalık ders çalışma saati & $\% 50$ (1-5 saat), \% 38 (6-10 saat), \% 12 (11 ve üzeri) \\
\hline Haftalık sosyal aktivite saati & $\% 50$ (1-5 saat), \% 38 (6-10 saat), \% 12 (11 ve üzeri) \\
\hline Başarı Ortalaması & $\% 15[1.00-2.00], \% 48[2.01-3.00], \% 37$ [3.01-4.00] \\
\hline Üniversitede kaçıncı yılında & $\% 58[1,2], \% 32[3,4], \% 10[5,6], \% 0[7$ ve üzeri] \\
\hline Kayıtlı olduğu fakülte & $\begin{array}{l}\text { \% } 65 \text { Mühendislik ve Doğa Bilimleri Fakültesi, } \\
\text { \% } 45 \text { Sanat ve Sosyal Bilimler Fakültesi }\end{array}$ \\
\hline Yaş Ortalaması & 20 \\
\hline Yerleşim & $\begin{array}{l}\text { \% } 76 \text { metropol (istanbul, ankara, izmir), \% } 19 \text { il, \% } 5 \\
\text { ilçe/kasaba, \% } 0 \text { köy }\end{array}$ \\
\hline Yaşadığı yer (barınma) & $\begin{array}{l}\% 42 \text { aile ile, \% } 1 \text { akraba yanında, \% } 2 \text { evde-yalnız, } \\
\% 1 \text { evde-arkadaşla, \% } 54 \text { yurtta }\end{array}$ \\
\hline Annenin eğitim durumu & $\begin{array}{l}\% 5 \text { ilköğretim, \% } 31 \text { lise, \% } 52 \text { üniversite, \% } 8 \text { yüksek } \\
\text { lisans, \% } 4 \text { doktora }\end{array}$ \\
\hline Babanın eğitim durumu & $\begin{array}{l}\% 3 \text { ilköğretim, \% } 16 \text { lise, \% } 61 \text { üniversite, \% } 14 \text { yüksek } \\
\text { lisans, \% } 6 \text { doktora }\end{array}$ \\
\hline
\end{tabular}

\section{Veri Toplama Aracı}

Kimlik Ölçeği’nin üç alt ölçeği vardır: (1) Kişisel Kimlik Ölçeği (10 madde); (2) Toplumsal Kimlik Ölçeği (7 madde); (3) Kolektif 
Kimlik Ölçeği (8 madde). Ölçekte 10 dolgu maddesi olmak üzere toplam 35 madde kullanılmaktadır. Kimlik Ölçeği üniversite öğrencilerine bireysel olarak uygulanmıştır. Katılımcılardan her maddeye 1'den (benim kim olduğum için önemsiz) 5'e (benim kim olduğum için her zaman çok önemli) kadar uzanan Likert tipi bir ölçek üzerinde yanıt vermeleri istenmiştir. Dolayısıyla, tüm ölçekten alınan en küçük puan 25 , en yüksek puan ise $125^{\prime}$ tir.

Kişisel Kimlik Alt Ölçeği aşağıdaki 10 maddenin değerini ölçmektedir:

1. Bireyin kişisel değerleri ve ahlâki standartları

2. Bireyin kişisel hayalleri ve düşleri

3. Geleceğe yönelik kişisel amaçları ve beklentileri

4. Bireyin heyecanları ve duyguları

5. Bireyin düşleri ve görüşleri

6. Bireyin korku ve kaygılarıyla baş etme tarzı

7. Bireyin başkalarından farklı biri olarak kendine özgü bir kişiliğe sahip olması

8. Hayattaki değişikliklere rağmen özde aynı kalmaya devam edileceği bilgisi

9. Bireyin kendisiyle ilgili bilgi ve düşünceleri

10. Bireyin kişisel olarak kendilik değeri, kendi hakkındaki özel görüşü.

Bu maddeler kimlik ölçeğindeki sırasıyla 2, 5, 8, 11, 14, 17, 19, 21, 24 ve 28 . maddelerdir.

Sosyal Kimlik Alt Ölçeği aşağıdaki 7 maddenin değerini ölç- 
mektedir:

1. Bireyin başkalarına göre popüler olması

2. Bireyin söylediği ve yaptığı şeylere başkalarının gösterdiği davranış tarzları

3. Bireyin fiziksel görünüşü

4. Başkalarının birey hakkında ne düşündüğü

5. Başkalarına göre kişinin çekiciliği

6. Bireyin jestleri, başkaları üzerinde oluşturduğu izlenimleri

7. Bireyin başkalarıyla bir araya geldiği zaman, sergilediği davranış tarzı olan sosyal davranışı.

Bu maddeler kimlik ölçeğindeki sırasıyla 3, 6, 9, 12, 15, 22 ve 25. maddelerdir.

Kolektif Kimlik Alt Ölçeği aşağıdaki 8 maddenin değerini ölçmektedir:

1. Kişinin, ailesinin kuşağının bir üyesi olması

2. Kişinin ırk ve etnik özgeçmişi,

3. Kişinin dini,

4. Kişinin yaşadığı ve büyüdüğü yerler,

5. Kişinin topluma ait olma duygusu,

6. Kişinin ülkesinden gurur duyması ve bir vatandaş olarak övünme duygusu,

7. Kişinin politik konulara ilgisi ve politik etkinlikleri,

8. Kişinin bölgesel aksanı, telaffuzu ve ikinci dil bilmesi

Bu maddeler kimlik ölçeğindeki sırasıyla 4, 7, 10, 13, 23, 26, 31 ve 33. maddelerdir. 


\section{Kimlik Ölçeği’nin Geçerlik ve Güvenirlik Çalışması}

Kimlik Ölçeği, Coşkun (2004) tarafindan Türkçe'ye çevrilerek geçerlik ve güvenirlik açısından incelenmiştir. Araştırmaya 275 üniversite öğrencisi katılmıştır. Ölçeğin yapı ve ölçüt geçerliğine ilişkin bulgular, alt ölçeklerin (kişisel, sosyal ve kolektif kimlik) tek bir yapıyı yansıttığını, birbiriyle uyum içinde ve diğer ölçeklerden farklı bir yapısının olduğunu (Berzonsky, 1994; Cheek ve ark., 1994; Coşkun, 2004; Tropp, 1992), testin tamamına, alt ölçeklerin iç tutarlılığına ve puan değişmezliğine ilişkin güvenirlik (test tekrar test) katsayılarının $(N=160)$ yeterli düzeyde olduğunu ortaya koymaktadır (Coşkun, 2004). Maddelerin bulundukları alt ölçekle korelasyon katsayılarına (madde-toplam korelasyonlarına) bakıldığında, kişisel, sosyal ve kolektif kimlik için sırasıyla .52, .51 ve .67 olduğu görülmektedir. (Coşkun, 2004). Ölçeğin güvenirlik çalışmasında, ölçeğin Cronbach alfa katsayısı ile belirlenen iç tutarlık güvenirliği .79 bulunmuş; katsayılarının kişisel kimlik alt ölçeği için .76, sosyal kimlik alt ölçeği için .78 ve kolektif kimlik için .80 olduğu rapor edilmiştir (Coşkun, 2004).

\section{Bulgular}

Kimlik ölçeğinin üç alt boyutu olan kişisel kimlik, sosyal kimlik ve kolektif kimlik boyutlarına ait ortalamalara bakıldığında, kişisel kimlik ortalaması sosyal kimlik ve kolektif kimlik ortalamasından daha yüksektir. Tablo 1 kimlik ölçeğine ait tanımlayıcı istatistiği sunmaktadir.

Tablo 1. Kimlik Alt Ölçeklerine Ait Tanımlayıcı İstatistikler 


\begin{tabular}{lcc}
\hline & Ortalama $(N=505)$ & Standart Sapma \\
\hline Kişisel kimlik & 41.48 & 6.27 \\
Sosyal kimlik & 22.47 & 5.13 \\
Kolektif kimlik & 23.35 & 5.95 \\
\hline
\end{tabular}

Kimlik ölçeğinin alt boyutları ve demografik bilgiler arasındaki korelasyon sonuçlarına göre, bütün alt kimlik ölçekleri arasında yüksek düzeyde anlamlı bir ilişki vardır. Tablo 2, demografik bilgiler ve kimlik ölçeğinin alt ölçekleri arasındaki korelasyon sonuçlarını sunmaktadır. Demografik bilgilerden yaş, okul başarı ortalaması, okulda kaçıncı yılında olduğu, hayatını en uzun geçirdiği yerleşim yeri, şu anda yaşadığı yer (barınma), annenin eğitim durumu, babanın eğitim durumu bilgileri ile alt kimlik ölçekleri arasında anlamlı bir ilişki bulunamamıştır. Alt kimlik ölçekleri ile demografik bilgiler arasında anlamlı ilişkiler olan maddeler şunlardır:

1. Kişisel kimlik ile cinsiyet arasında 0.01 seviyede ( $r=-0.29)$, kayıtlı olduğu fakülte türü arasında 0.05 seviyede $(r=0.09)$, haftalık ders çalışma saati ve haftalık sosyal aktivite saati arasında 0.05 seviyede $(r=0.10)$ anlamlı ilişkiler vardır.

- Cinsiyet değişkeni açısından incelendiğinde, kadın olmak ile kişisel kimliğin ilişkili olduğu görülmektedir.

- Öğrencilerin kayıtlı oldukları fakülte ve kimlik göz önüne alındığında, Sanat ve Sosyal Bilimler Fakültesi'ne kayıtlı olmak ile kişisel kimlik puanındaki artışın, anlamlı ve pozitif yönde ilişkili olduğu görülmektedir. 
- Haftalık ders çalışma saati ve haftalık sosyal aktivite saati artıkçaü kişisel kimlik puanı artmaktadır.

2. Sosyal kimlik ile sosyal aktivite saati arasında 0.01 seviyede $(r=0.12)$ anlamlı bir ilişki vardır.

- Haftalık sosyal aktivite saati artıkça sosyal kimlik puanı artmaktadir.

3. Kolektif kimlik ile kaçıncı sınıfta olduğu arasında 0.05 seviyede $(r=-0.10)$ anlamlı bir ilişki varken ailenin gelir durumu ile 0.01 seviyede $(r=0.14)$ anlamlı bir ilişki vardır.

- Üst sınıflara geçildikçe kolektif kimlik puanı azalma göstermektedir.

- Ailenin geliri artıkça, kolektif kimlik puanının arttığı görülmüştür. 
Tablo 2. Pearson Korelasyon Sonuçları $(N=505)$

\begin{tabular}{lccc}
\hline Demografik Bilgiler & Kişisel & Sosyal & Kolektif \\
& Kimlik & Kimlik & Kimlik \\
\hline Cinsiyet & $-.29 * *$ & -.00 & -.03 \\
Sınıf & .05 & .01 & $-.10^{*}$ \\
Ailesinin geliri & .00 & .05 & $.14 * *$ \\
Haftalık ders çalışma saati & $.10 *$ & -.02 & .00 \\
Haftalık sosyal aktivite saati & $.10 *$ & $.12 * *$ & .00 \\
Başarı Ortalaması & .08 & -.06 & -.06 \\
Üniversitede kaçıncı yılında & .06 & -.00 & -.05 \\
Kayıtlı olduğu fakülte & $.09 *$ & -.01 & .04 \\
Yaş & .01 & -.01 & .01 \\
Yerleşim & .03 & -.03 & .02 \\
Yaşadığı yer (barınma) & -.02 & -.03 & .02 \\
Annenin eğitim durumu & .01 & .08 & -.08 \\
Babanın eğitim durumu & -.04 & .02 & -.04 \\
Kişisel kimlik & 1 & $.20 * *$ & $.23 * *$ \\
Sosyal kimlik & $.20 * *$ & 1 & $.43 * *$ \\
Kolektif kimlik & $.23 * *$ & $.43 * *$ & 1 \\
\hline$* \quad p=0.05, * * \quad p=0.01$ & & &
\end{tabular}

\section{Sonuç ve Tartışma}

Kimlik ölçeğinin alt boyutlarına ait bulgulara göre, kişisel kimlik ortalaması sosyal kimlik ve kolektif kimlik ortalamasından daha yüksektir. Bu bulgu, öğrencilerin kişisel kimliklerini ön plana çıkarma eğiliminde olduklarını ve kimlik oluşumunda kişisel kimlik özellikle- 
rinin daha baskın olduğu sonucunu düşündürüyor. Kimlik ölçeğinin alt boyutları ile demografik bilgilerden cinsiyet, sınıf seviyesi, ailenin gelir seviyesi, haftalık ders çalışma saati, haftalık sosyal faaliyetlere ayrılan zaman ve kayıtlı olduğu fakülte bilgileri arasında, anlamlı ilişkileri gösterir korelasyonlar vardır.

Öğrencilerin akademik aktivitelerine baktığımızda, ders çalışmak ile kişisel kimlik arasında anlamlı bir ilişki görülüyor. Öğrenciler ders çalışmaya daha fazla zaman ayırarak bireysel hedeflerini ön plana çıkarma eğilimindeler. Bununla birlikte, öğrencilerin sosyal aktivitelere katılımı ile hem kişisel kimlikleri hem de sosyal kimlikleri arasında ilişki olduğu gözlemlenmektedir. Öğrenciler sosyal faaliyetlere daha fazla zaman ayırarak, hem kendi kişisel hayalleri, beklentileri ve görüşlerini hem de sosyal davranışları, başkaları üzerinde oluşturduğu izlenimleri ve popülerliğini ön plana çıkarma eğilimindeler. Üniversite öğrencilerinin, üniversite yıllarında yaşadığı akademik ve sosyal deneyimleri, bir üniversiteli olarak kişisel ve sosyal kimliğinin oluşumunda etkili olmaktadır. Öğrenciler, üniversitede geçirdiği yıllar içinde, ait olduğu etnik köken, din, dil ve aileden taşıdığı özellikleri ön plana çıkarmayıp, gelecek için koyduğu bireysel hedefleri ve sosyal çevresi ile etkileşimi ön plana çıkarma eğilimindedirler. Dolayısıyla, öğrenciler üst sınıflara geçtikçe kolektif kimliklerinin geri planda kaldığı gözlemlenmektedir. Bu, öğrencilerin kendi korku ve kaygılarıyla baş etme tarzı, başkalarından farklı biri olarak kendine özgü bir kişiliğe sahip olma çabası ve sosyal çevresinden kabul görme arzusu ile ilişkili olabilir. Türkiye, kolektif bir toplum olmaktan bireysel bir toplum 
olmaya geçiş döneminde iken, yükseköğrenimdeki kadınların, kendilerini bireysel ifade etme davranışları ön plana çıkmaktadır.

Sanat ve Sosyal Bilimler Fakültesi'ndeki öğrencilerin sosyal kimliklerini ön plana çıkarmaları beklenirken, kişisel kimliklerini ön plana çıkarma eğiliminde oldukları görülmüştür. Bu, Sabancı Üniversitesi'nde Mühendislik ve Doğal Bilimleri Fakültesi öğrencilerinin, üniversite nüfusunun çoğunluğunu oluşturmaları ve fazladan temsil edilmeleri ile ilişkili olabilir.

Kişisel, sosyal ve kolektif kimlik üzerine yapılan çalışmalar, kimliğin bu üç boyutunun yüksek veya alçak belirginlik seviyelerinde nasıl işlev gördüğünü araştırmışlardır (Wade ve Brittan-Powell, 2000). Schlenker ve Weigold (1990)'un yaptığı araştırmaya göre, kişisel kimliği güçlü olan bir birey, sosyal, özerk ve eşsiz olma ihtiyacı hisseden biridir. Fakat sosyal kimliği güçlü olan bir birey sosyal olmasına rağmen, özerk olmaktansa gruba uygun davranmaya çalışır ve grubun yapabileceği olumsuz değerlendirmelerden korkar (Wade ve Brittan-Powell, 2000). Ayrıca, kişisel kimliğin elde edilmiş ego kimliğiyle alakalı olduğu, sosyal kimliğin ise, engel olunmuş ego kimliğiyle ilişkili olduğu düşünülür (Berzonsky, Trudeau ve Brennan, 1988; Wade ve Brittan-Powell, 2000). Genel olarak güçlü kişisel kimliğin, kişisel gerekçe ve yarara göre karar verme, güçlü sosyal kimliğin ise sosyal gerekçe ve yarara göre karar verme ile alakalı olduğu söylenebilir (Wade ve Brittan-Powell, 2000).

Ailenin geliri arttıkça, kolektif kimlik özelliklerinin geri planda 
kalması beklenirken, kolektif kimliğin ön plana çıktığı gözlemleniyor.

Sabancı Üniversitesi’ndeki öğrencilerin aile geliri dağılımı göz önüne alındığında, ailelerin \% 48'i orta düzey gelire, \% 50'si ise yüksek ve çok yüksek gelire sahiptir. Öğrencilerin, hayatlarını geçirdikleri yerleşim yerine bakıldığında \% 76'sı metropollerden (İstanbul, Ankara, İzmir), \% 19'u diğer çevre illerden gelmektedir. Öğrenciler, yüksek gelirli bir aileden olsalar bile, topluma ait olma duygularının ve kendine güvenlerinin ön plana çıktığı görülmektedir. Kolektif kimlik ile kişinin kendine dair algısı ve güveni arasındaki ilişki de, birçok sosyal ve demografik gruptan gelen bireyler arasında araştırılmıştır (Hengst, 1997; Marmarosh ve Corazzini, 1997; Wright ve Forsyth, 1997). Bu araştırmaların sonucuna göre, kişi kolektif kimliğini kendine dair alg1sında önemli veya değerli buluyorsa, kişinin kendine güveni artmaktadir (Wade ve Brittan-Powell, 2000).

Kimlik konusundaki bazı çalışmaların (Berman, Kennerley ve Kennerley, 2008; Ferrer-Wreder, Montgomery ve Lorente, 2003) önerdiği gibi, üniversite öğrencilerinin kimlik gelişimini destekleyecek programlar sağlanmalıdır. Bu araştırmanın sonuçları, kimlik gelişimini desteklemek için hazırlanan programlar ve öğrenci bireysel destek programları göz önünde bulundurularak, gerekli eğitim seminerlerinde ve destek programlarında kullanılabilir. Bu programlar, öğrencilerin üniversite hayatlarının kalitesini geliştirmekte ve kimlik oluşumlarını desteklemekte önemli bir rol oynayabilir. 


\section{Kaynakça}

Arnett, J. J. (2000). Emerging adulthood: A theory of development from the late teens through the twenties. American Psychologist, $55,469-480$.

Arnett, J. J. (2001). Conceptions of the transition to adulthood: Perspectives from adolescence to midlife. Journal of Adult Development, 8,133-143.

Arnett, J. J. (2004). Emerging adulthood: The winding road from the late teens through the twenties. New York: Oxford University Press.

Berman, S. L., Kennerley, R.J. ve Kennerley, M. A. (2008). Promoting adult identity development: A feasibility study of a university-based identity intervention program. Identity: An International Journal of Theory and Research, 8,139-150.

Berzonsky, M. D. (1994). Self-identity: The relationship between process and content. Journal of Research in Personality, 28, 453-460.

Berzonsky, M. D., Trudeau, J. V. ve Brennan, F. X. (1988). Socialcognitive correlates of identity status. Paper presented at the second biennial meeting of the Society for Research on Adolescence, Alexandria, Virginia.

Briggs, S. R. ve Cheek, J. M. (1986). The role of factor analysis in the development and evaluation of personality scales. Journal of Personality, 54, 106-148.

Cheek, J. M. (1982). Aggregation, moderator variables, and the validity of personality tests: A peer-rating study. Journal of Personality and Social Psychology, 43, 1254-1269. 
Cheek, J. M. (1983). The aspects of Identity Questionnaire: Revised scales assessing personal and social identity. Unpublished manuscript. Massachusetts: Wellesley College.

Cheek, J. M. (1989). Identity orientations and self-interpretation. D. M. Buss ve N. Cantor (Ed.), Personality psychology: Recent trends in emerging directions içinde (275-285). New York: Springer-Verlag.

Cheek, J. M. ve Briggs, S. R. (1982). Self-consciousness and aspects of identity. Journal of Research in Personality, 16, 401-408.

Cheek, J. M. ve Hogan, R. (1983). Self-concepts, self-presentations, and moral judgments. J. Suls ve A. G. Greenwald (Ed.), Psychological perspectives on the self (2. bask1) içinde (249-273). Hillsdale, NJ: Lawrance Erlbaum Associates.

Cheek, J. M., Tropp, L. R., Chen, L. C., ve Underwood, M. K. (1994). Identity orientations: Personal, social, and collective aspects of identity. Paper presented at the 104th Annual Convention of the American Psychological Association, Los Angeles, California.

Cheek, J. M. ve Tropp, L. R. (1995). The aspects of Identity Questionnaire: History and bibliography (2. bask1). Massachusetts: Wellesley College.

Cheek, J. M., Underwood, M. K. ve Cutler, B. L. (1985). The aspects of Identity Questionnaire (III). Unpublished manuscript. Massachusetts: Wellesley College.

Coşkun, H. (2000). The effects of out-group comparison, social context, intrinsic motivation, and collective identity in brainstorming groups. Yayınlanmamıs doktora tezi, The University of Texas at Arlington.

Coskun, H. (2004). Kimlik ölçeğinin bir Türk örnekleminde geçerlik ve 
güvenirlik çalışması. Türk Psikoloji Yazıları, 7(14), 49-60.

Côté, J. E. (1996). Sociological perspectives on identity formation: The culture-identity link and identity capital. Journal of Adolescence, 19, 419-430.

Côté, J. E. (2006). Identity studies: How close are we to developing a social science of identity? An appraisal of the field. Identity: An International Journal of Theory and Research, 6, 3-26.

Côté, J. E. ve Levine, C. (2002). A critical examination of the ego identity status paradigm. Developmental Review, 8, 147-184.

Côté, J. E. ve Roberts, S. (2003). Monitoring the transition to adulthood: The Identity Stage Resolution Index. Paper presented at the annual meeting of the Society for Research on Identity Formation, Vancouver, BC, Canada.

Demir, G. Ö. (2009). Üniversite öğrencilerinin kimlik gelişiminde sosyal ve kimlik sermayelerinin rolü. Yayınlanmamış doktora tezi, Hacettepe Üniversitesi Sosyal Bilimler Enstitüsü.

Erikson, E. H. (1950). Childhood and society. New York: W. W. Norton.

Erikson, E. H. (1963). Childhood and society. New York: W. W. Norton.

Erikson, E. H. (1968). Identity, youth and crisis. New York: Norton.

Ferrer-Wreder, L., Montgomery, M. J. ve Lorente, C. C. (2003). Identity promotion in adolescence. Gullotta, T., Bloom, J. ve Adams, G. (Ed.), Encyclopedia of primary prevention and health promotion içinde (600-607). Hingham, MA: Kluwer Academic/Plenum. 
Hengst, H. (1997). Negotiating “us”and “them”: Children's constructions of collective identity. Childhood: A Global Journal of Child Research, 4, 43-62.

Hogan, R. ve Cheek, J. M. (1983). Identity, authenticity, and maturity. T. R. Sarbin ve K. E. Scheibe, (Ed.), Studies in social identity içinde (339-357). New York: Praeger.

Kowalski, R. M. ve Wolfe, R. (1994). Collective identity orientations, patriotism, and reactions to national outcomes. Personality and Social Psychology Bulletin, 20, 533-540.

Lamphere, R. A. ve Leary, M. R. (1990). Private and public self-processes: A return to James's constituents of the self. Personality and Social Psychology Bulletin, 16, 717-725.

Luyckx, K., Schwartz, S. J., Soenens, B., Vansteenkiste, M. ve Goossens, L. (2010). The path from identity commitments to adjustment: motivational underpinnings and mediating mechanisms. Journal of Counseling \& Development, 88, 52-60.

Marcia, J. E. (1966). Development and validation of ego identity status. Journal of Personality and Social Psychology, 5, 551-558.

Marmarosh, C. L. ve Corazzini, J. G. (1997). Putting the group in your pocket: Using collective identity to enhance personal and collective self-esteem. Group Dynamics, 1, 65-74.

Meilman, P. W. (1979). Cross-sectional age changes in ego identity status during adolescence. Developmental Psychology, 15, 230231.

Miller, M. L. ve Thayer, J. F. (1988). On the nature of self-monitoring: Relationship with adjustment and identity. Personality and Social Psychology Bulletin, 14, 544-553. 
Penner, L. A. ve Wymer, W. E. (1983). The moderator variable approach to behavioural predictability: Some of the variables some of the time. Journal of Research in Personality, 17, 339-353.

Schlenker, B. R. ve Weigold, M. F. (1990). Self-consciousness and self-presentation: Being autonomous versus appearing autonomous. Journal of Personality and Social Psychology, 59, 820828.

Schwartz, S. J. (2006). Predicting identity consolidation from self-construction, self-discovery, and agentic personality. Journal of Adolescence, 29, 777-793.

Schwartz, S. J. (2007). The structure of identity consolidation: Multiple correlated constructs or one super ordinate construct? Identity, 7 , $27-49$.

Schwartz, S.J., Zamboanga, B.L., Weisskirch, R.S. ve Wang, S.C. (2010). The relationships of personal and cultural identity to adaptive and maladaptive psychosocial functioning in emerging adults. The Journal of Social Psychology, 150(1), 1-33.

Stephen, J., Fraser, E. ve Marcia, E. (1992). Moratorium-achievement (MAMA) cycles in lifespan identity development: Value orientations and reasoning system correlates. Journal of Adolescence, $15,283-300$.

Tajfel, H. (1982). Social psychology of intergroup relations. Annual Review of Psychology, 33, 1-39.

Tajfel, H. ve Turner, J. C. (1986). The social identity theory of intergroup behavior. S. Worschel ve W. G. Austin (Ed.), Psychology of intergroup relations içinde (7-24). Chicago: Nelson-Hall.

Tropp, L. R. (1992). The construct of collective identity and its implications for the Wellesley College context. Bachelor's honors 
thesis, Massachusetts: Wellesley College.

Turner, J. C. (1978). Social comparison, similarity and ingroup-favoritism. H. Tajfel (Ed.), Differentiation between social groups: Studies in the social psychology of intergroup relations içinde (235-250). London: Academic Press.

Wade, J. C. ve Brittan-Powell, C. (2000). Male reference group identity dependence: support for construct validity. Sex Roles, 43(5/6), 323-340.

Wright, S. S. ve Forsyth, D. R. (1997). Group membership and collective identity: Consequences for self-esteem. Journal of Social and Clinical Psychology, 16, 43-56. 